\title{
The tests of effectiveness of Frostbuster under excessive weather conditions in an apricot plantation
}

\author{
Lakatos, L. ${ }^{1}$, Ancza, E. ${ }^{1}$, Szél, J. ${ }^{1}$, Soltész, M. ${ }^{2}$, Szabó, Z. ${ }^{1}$ \& Nyéki, J. ${ }^{1}$ \\ ${ }^{1}$ University of Debrecen Centre for Agricultural and Applied Economic Sciences, \\ H-4032 Debrecen, Böszörményi út 138., Hungary \\ ${ }^{2}$ Collage of Kecskemét, Faculty of Horticulture, H-6000 Kecskemét, Erdei Ferenc tér 1-3.
}

\begin{abstract}
Summary: Frostbuster is a new system, engine and technology, developed to protect fruit plantations from the frost damage. In order to raise domestic experiences and measurements, experimental approach has been initiated to prove the utility of the system under excessively low temperature in the plantation of the Siófoki Gyümölcstermesztési Zrt (Fruit Growing Co. Siófok). The first opportunity ensued in the night of February $23-24,2011$, when the temperature sank to $12^{\circ} \mathrm{C}$ below zero. The question was to see whether we could prevent the drop of temperature by the frostbuster technique. The margin of an anticyclone staying on East Europe secured a stable condition to make tests. The only difference from the imaginable conditions of dangerous frosts was the heat keeping capacity of trees was weak, much inferior than compared with trees in full boom. As a consequence, the tree rows represented much lower heat-capacity and cooled down much quicker than blooming trees in springtime, i.e. their temperature was more variable. The other difference was, compared with an episode in spring that the hard frost lasted much longer than usually in spring. For testing the system, those conditions had even more advantage. Six meteorological stations helped us in measurement. Data-collectors were timed to 1 minute distances and the bulk of data proved to be beneficial for testing the Frostbuster. The results prove that the system is adequate to keep the temperature continuously higher than the surrounding field under excessively low temperatures. Further measurements are still needed to find the optimal solutions fitting to the growing site and its microclimate. Results presented offer a basis of further proofs.
\end{abstract}

Key words: Frostbuster, prevention of frost damage, frost protection

\section{Introduction}

Frost protection was always a serious challenge in fruit and vegetable production. A lot of literature attacked the problem first with the prediction of frost weather (Young 1920), Hagood (1967) or estimating the expected temperature minima for the next night (Allen, 1957). Beginning with the 1970-es, new technical tools and systems have been tested (Bagdonas et. al., 1978). Let alone the methods based on heating, other approaches have been used, e.g. the wind making (Crawford, 1965) and water spraying (Gerber \& Martsolf, 1979; Synder, 1986). Heating systems had nowadays another bust and became popular by the growers, because it is mobile and need no special technical equipment. The Frostbuster seemed by that reason to be feasible. Cooling by radiation during the winter is seldom windless whereas in spring, always the complete lull is generally the main danger. As in most cases, the late spring frosts are not regular, fortunately not every year, and rarely lower than $5^{\circ} \mathrm{C}$, it was an obvious argument to make the tests with the Frostbuster under winter conditions. The only problem is that the trees are still leafless so the physical conditions are different. By that reason, conditions in autumn at the early frosts would be much more representative for our purpose. With the heat caching capacity of the leafy tree, like a tree at full bloom with the open petals, the latent and sensible heat carrying process is much more important. By that reason, more heat energy will be captured within the canopies of the plantation, around the trees, which diminishes the risk of damage significantly.

\section{Materials and methods}

The essence of an effective application of the method is that it should be adapted to the structure of plantings in Hungary and the generally accepted microclimatic conditions. The moving speed of the tractor on a thoughtfully planned rout should keep to the optimal time to maintain the raised temperature for a maximal length of time, meanwhile to economise the energy too. The producer's recommendation proposes $7-8$ ha per tractor of course is not valid for lower temperatures. If the expected frost were 1 to $3{ }^{\circ} \mathrm{C}$ below zero, the area could be much larger than when the minimum is $7^{\circ} \mathrm{C}$ below zero. At the beginning, the expected minimum should be known by consulting the OMSZ (Countrywide Meteorological Service). Locally, the flats and ditches are more affected, where windless patches could appear. The thorough knowledge of the landscape and the winds is also recommended. We performed macro- and micrometeorological measurements, and the itinerary of the path of treatment was planned according to those date. 
Temperature changes, relative air humidity and wind records are registered hourly; the expected minimum is computed from those data. This is an index, which serves to calculate the optimal moving speed of the tractor carrying the Frostbuster during the night. The cooling down index, moving speed and the optimal rout through the plantation are the parameters necessary for an effective frost protection. All those activities are concentrated to the Fruit growing Co. at Siófok. Trees were planted in 1988, the planting design is $3.5 \times 5.5 \mathrm{~m}$, the trees have been trained to a crown form umbrella of Papp.

\section{The principle of operation}

The essence of FROSTBUSTER is a gas-turbine, which warms up the air, which was invented by the aircraft building industry. As an opposite aim of our turbine is not the production of moving energy but of producing heat. The tractor carrying the turbine should move at 540 revolutions per minute, the output $55 \mathrm{HP}$ (horse power). The maximum carrying power of the turbine is $150 \mathrm{~m}$ and the machine consumes $30 \mathrm{~kg}$ propane gas per hour.

The FROSTBUSTER blows the warm air downwards to the trees. The air is at the mouth between 80 and $100^{\circ} \mathrm{C}$, but one metre away $20^{\circ} \mathrm{C}$ already, does not harm the plants. The air blown out rises to $1 \mathrm{~m}$ height and forms a so called "air bell", which replaces the cold air and prevents its return to the inner parts of the plantation.

In order to counteract the heat loss by radiation of long wave length, the engine should start at $1^{\circ} \mathrm{C}$ above zero already. The prevention of frosts needs close information on the growing site, the extension and form of the plot. Regular square form is most advantageous. Under normal conditions up to $70 \mathrm{~m}$ distance is the effective from the machine. It is important to move on the same path every 10 minutes interval. If the moving speed is $8 \mathrm{~km} / \mathrm{h}$, the effect is to keep the temperature raised by $2^{\circ} \mathrm{C}$. After that the cooling is a very slow process.

According the manufacturer's recommendation, the frost protective effect is valid at full bloom until $-5^{\circ} \mathrm{C}$ and when blossom buds are still red until $-9^{\circ} \mathrm{C}$. After one hour long activity of the engine, the danger was overcome perfectly.

As soon as the temperature reached the desired degree (and the temperature rose over the critical threshold), the machine may stop

Effect and profitability of FROSTBUSTER is based on the variation of temperature induced by the machine, and the decline of relative air humidity. The reduced humidity diminishes the risk of appearing ice crystals. The variation of temperature is more advantageous than keeping the temperature continuously above zero temperature. In that case, the energy needed was 10 times less than in all other frost protection systems. By this method almost all possible frost threats could be averted. Results were perfect below -8 $\mathrm{C}^{\circ}$ too. The maximum output of the engine is built up after one hour long activity.
Advantage of the system is its perfect mobility; it is ready to move to another site any time, easy manipulation and cheap costs for service and durable because simple. It does not need much energy, costs of its use are low. No permission is necessary for its use and could be exploited for other aims. It does not pollute the environment. All other systems of frost protection are much more expensive by around $300 \%$.

FROSTBUSTER is used in the US since 1997. The site of the idea was the University of California Davis. In Europe, Tom Deckers and his staff worked in Belgium P.C.F. In South America the machine received the title ,Ideal solution against frosty nights"

\section{Technical data}

Total length with and without the pulling bar: $3650 / 3050$ mm; Width $1530 \mathrm{~mm}$; Height with and without wheels 1750$1450 \mathrm{~mm}$; Output of the fan, max. revolution per minute 6.8 M3 /sec, $2.400 \mathrm{rpm}$, TLT max. $540 \mathrm{rpm}$; Gas burner, propane gas; Gas bottles 6x35 kg; Max. temperature $100^{\circ} \mathrm{C}$; Max. temp. at 1 metre distance $20^{\circ} \mathrm{C}$; norms of security CEE/CE; Carrying power is $110 \mathrm{~m}(2 \times 55 \mathrm{~m})$; Max. area $10 \mathrm{ha}$; Efficiency of the tractor 65HP; Temperature tested: $-8 \mathrm{C}^{\circ}$; Gas consumption 30-40 kg/hour; Weight (empty) $720 \mathrm{~kg}$.

In the recommendations of FROSTBUSTER technology, the 7-8 ha supposes a special path, which should be followed by the driver. The path should be planned as adapted to local conditions, relative air humidity, actual temperature, etc. The effectiveness and costs are much dependent on the quality of the path planned and conditions recognised.

\section{Measurements at Siófok}

At the end of winter, we attempted an experimental action under excessive conditions. In the plantation of the Gyümölcstermesztési Zrt. Company, at Siófok, was the locality of using the Frostbuster system.

The temperature was during the whole day below zero, and the movement of air was shown in the Figure presented.

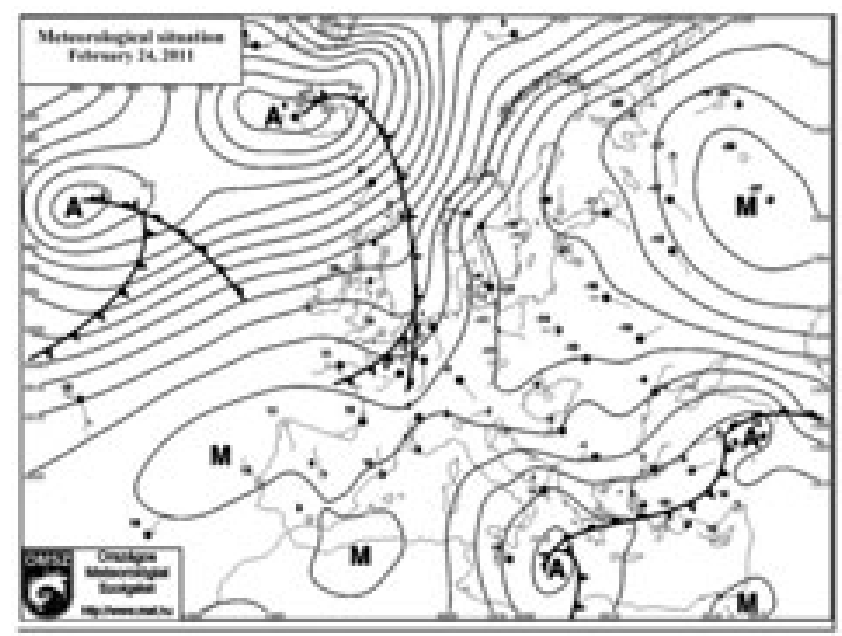




\section{The process of measurement}

Just after sunset, at 20 o'clock, measurements have been started the evening of February 23, and finished at 8 o'clock morning of Febr. 24. The control station has been located at a remote distance away from the points of measurements in order to avoid the influence of the Frostbuster. On a geographical map, we attempted to show the meteorological situation of the continent. Figure 1 is a design of the apricot plantation with the path planned for the itinerary of the tractor carrying the gas turbine of Frostbuster. First, the engine crossed the path indicated to temperate the area of plantation selected, then those rows are aimed, where the points of measurement are distributed. Subsequently, a special route served over one hour to go along the 1-2 and then the $2-3$ rows to and fro, after that to the middle of the plantation. Finally, the whole route was repeated once more.

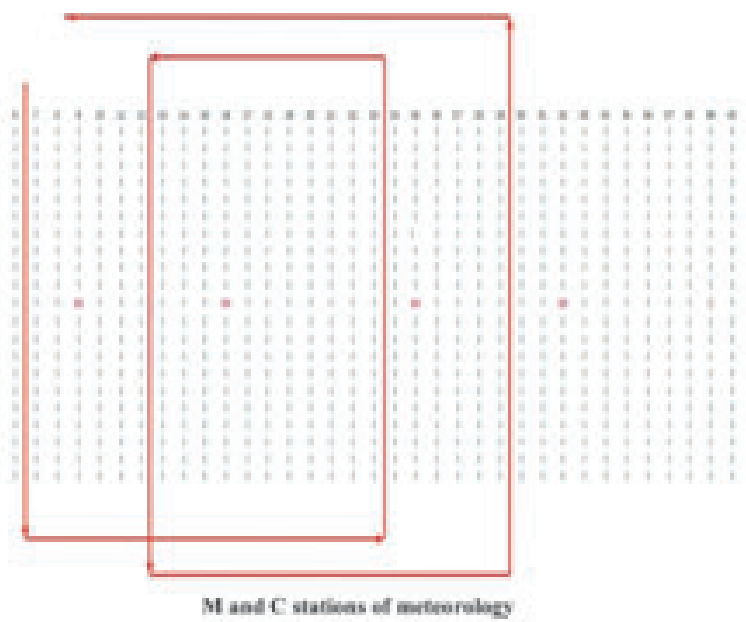

Legends: $123 \ldots 40$ : the number of rows in the plantation. M: points of measurement; $\mathbf{C}$ : check point of measurement. Itinerary designed for the engine of Frostbuster $\rightarrow$

Figure 1. The plan of the plantation with the position of stations of measurements and the path followed by the engin of Frostbuster. /Siófok, 2011. February 23-24/

\section{Results}

The implements measured every minute, so tiny changes are also perceived. In Figure 2, it is obvious that the M and C stations measured the same values, whereas the differences during the night reached the $5^{\circ} \mathrm{C}$ level. Because of the lack of foliage and flowers on the trees, this difference must be appreciated much more. Eve at the lowest point around sunrise, the $3^{\circ} \mathrm{C}$ difference could be maintained on the area treated.

As in Figure 3, the records, $\mathrm{M}$ and $\mathrm{C}$, were identical at the beginning of the experiment, but visualised the effect of Frostbuster throughout the night. The distance from the path of treatments was the cause of different movement of curves. The steady effect of warming up starting from the direction of the pathway and reached the rows further away gradually but with a less steep curve, as the energy content of the system increased continuously.

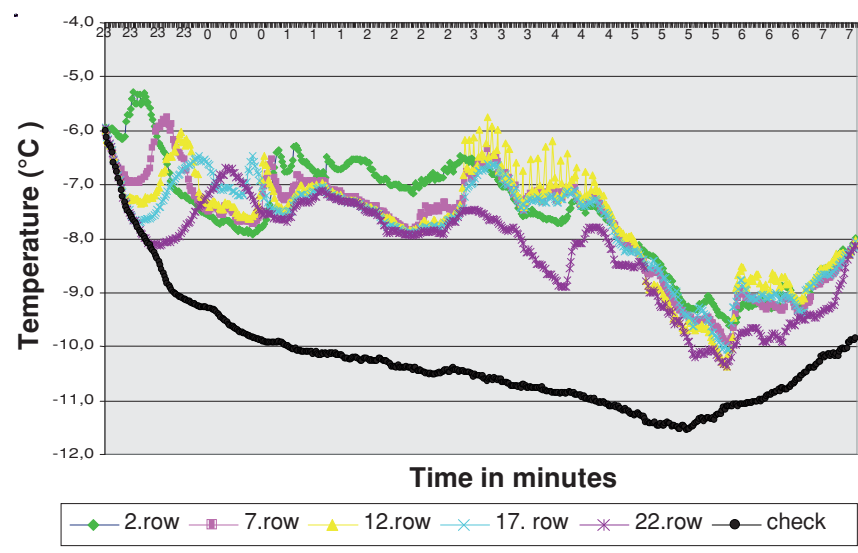

Figure 2. Temperatures measured in the plantation during the whole night at the different points of the rows of the area treated/Siófok, 2011. Febr. $23-24 /$

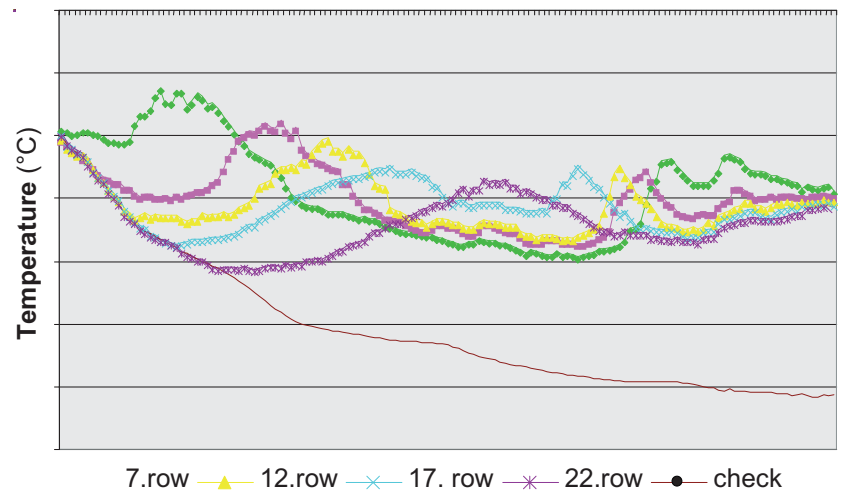

Figure 3. Changes in temperature after the first round completed by Frostbuster at the beginning of the cycle of measurement/Siófok, 2011. Febr. 23-24/

In Figure 4, we see the air temperatures increasing as the heating machine moved to and fro on the same rows. On the figure, it is the particularly low temperature, which causes the drastic cooling down because lack of foliage and flowers on the trees, which means reduced capacity to conserve heat.

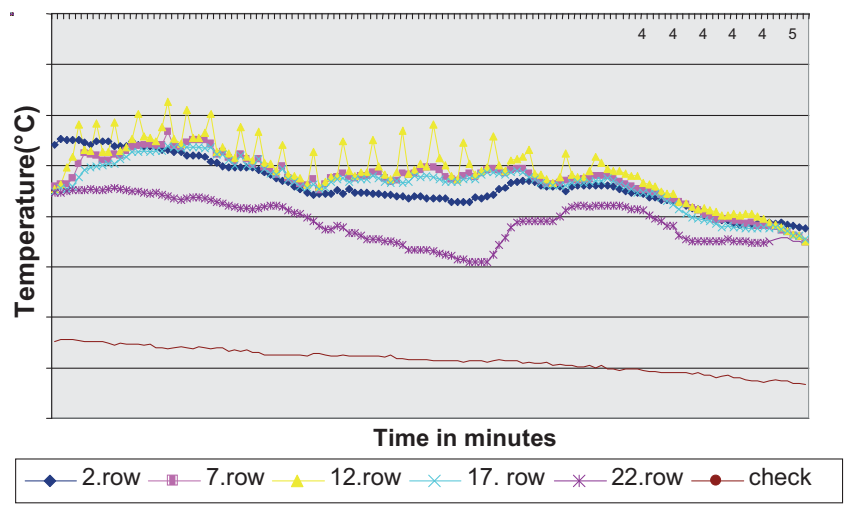

Figure 4. The movement of the Frostbuster, to and fro, in the $12^{\text {th }}$ row extended its effect to the whole plantation treated. /Siófok, 2011. Febr. 23-24/

The effectiveness of Frostbuster depends on the optimum of the quality of the path planned and the exact and continuous speed chosen. As long as we wanted to temperate 
the earlier warmed up area, the temperature difference between the two extremities of the area should be larger than $2.5^{\circ} \mathrm{C}$-t. If the middle of the treated area is considered the difference will be $1.5^{\circ} \mathrm{C}$ (Figure 5).

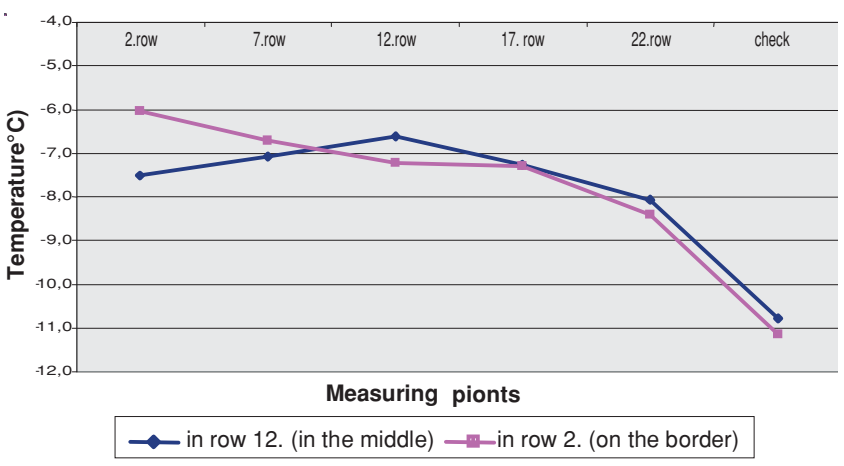

Figure 5. Effect of moving to and fro of the machine at the margin ( $2^{\text {nd }}$ row) or at the middle $\left(12^{\text {th }}\right.$ row) of the plantation on different parts of the area protected /Siófok, 2011. Febr. 23-24/

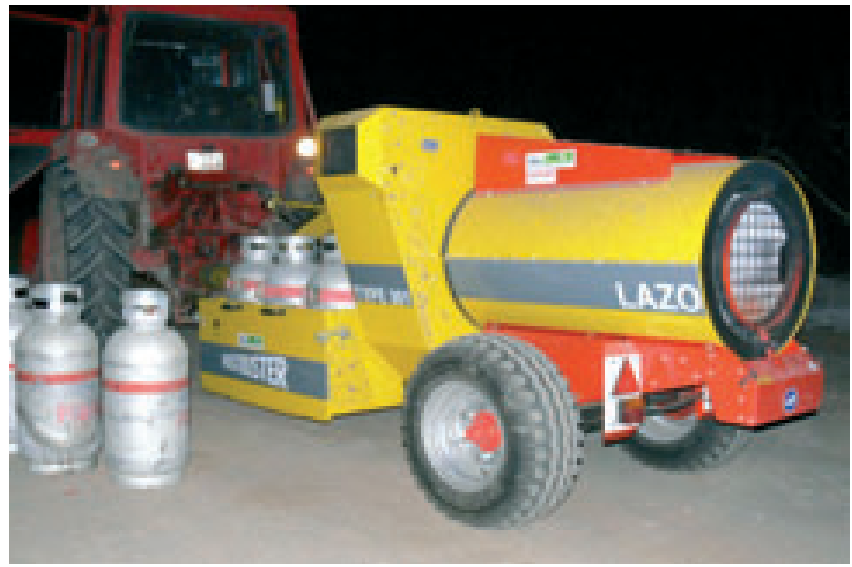

Picture 1. Frostbuster with gas bottles ready to use.

During the treatment three times three times an interruption is needed about (about 20 minutes each) for the replacement of the new gas-bottles.

Until sunrise, the temperature of the atmosphere of plantation has been raised successfully by $3-4{ }^{\circ} \mathrm{C}$

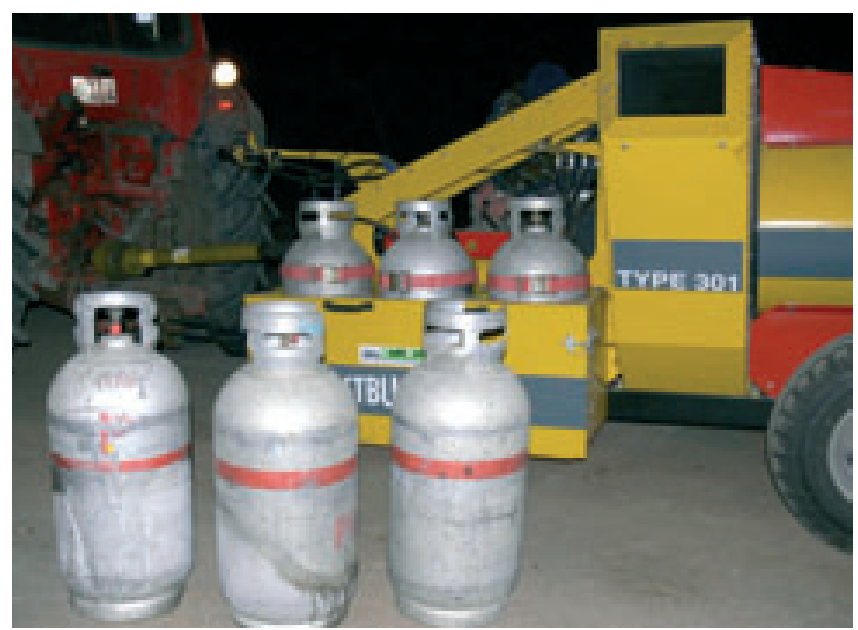

Picture 2. Replacement of bottles at sunrise

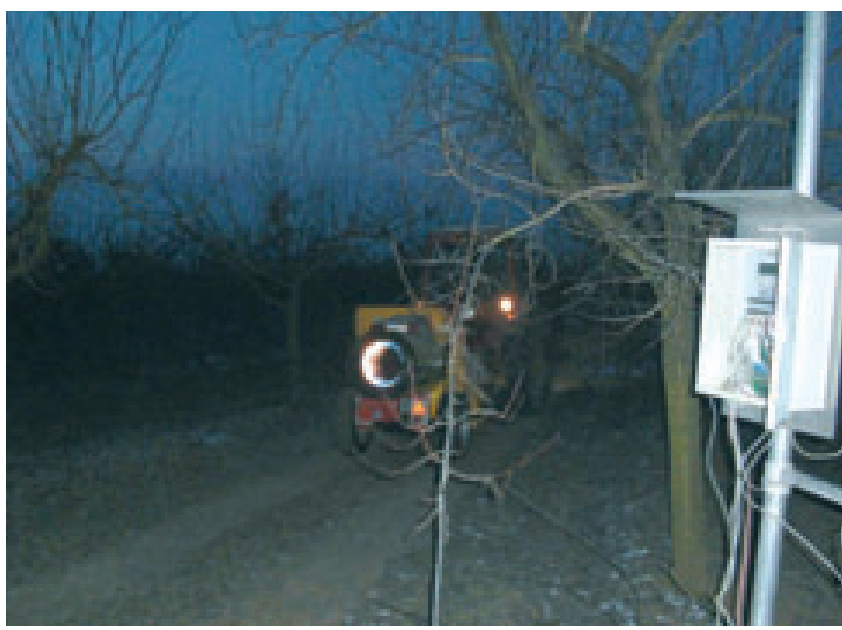

Picture 3. Frostbuster and the meteorololgical station during the experimental operation

Measurements were finished one hour after sunrise.

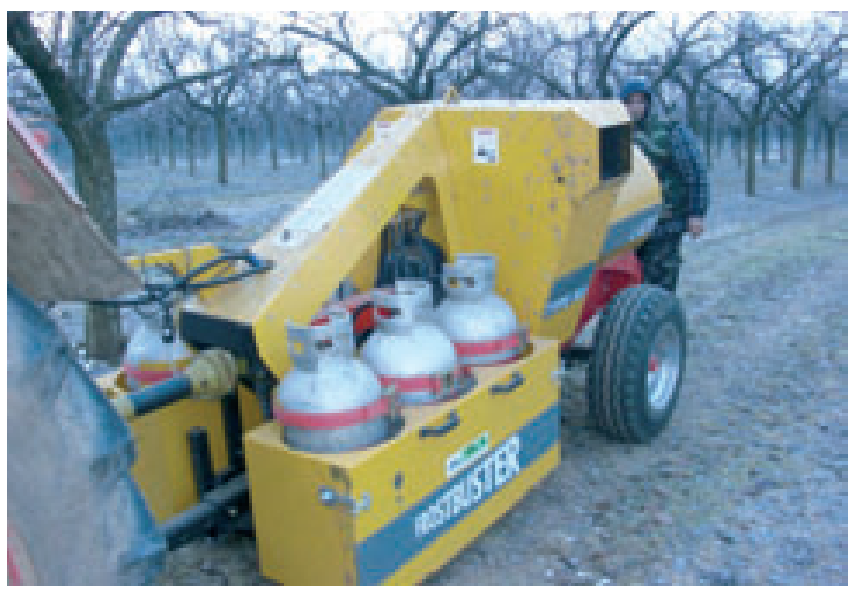

Picture 4. End of the experimental measurements in the morning hours

The history of meteorological situation during the measurements went according to the following happenings.

\section{Conclusions}

For the use of Frostbuster in the future, the local site and type of plantation are to be taken into account. The present report was concentrated to the apricot plantation of the Gyümölcstermesztési Zrt. Company at Siófok. The results proved the feasibility of frost protection under much colder conditions than expected under conditions of springtime after bud burst and blooming of trees. Further attempts are planned also in the autumn or in winter with the precondition that the low temperature is not transported by air (being "advective") but caused by radiation at full wind lull during cloudless night.

\section{Acknowledgement}

Research was sponsored by NFÜ TECH_08-A3/2-20080373 and TECJ_08-A4/2-2008-0138 grants. 


\section{Maximum temperatures \\ February 23,2011}

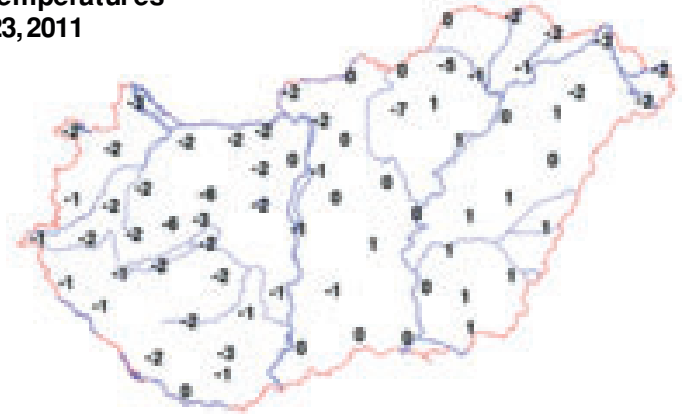

\section{Sunny hours}

February 23, 2011
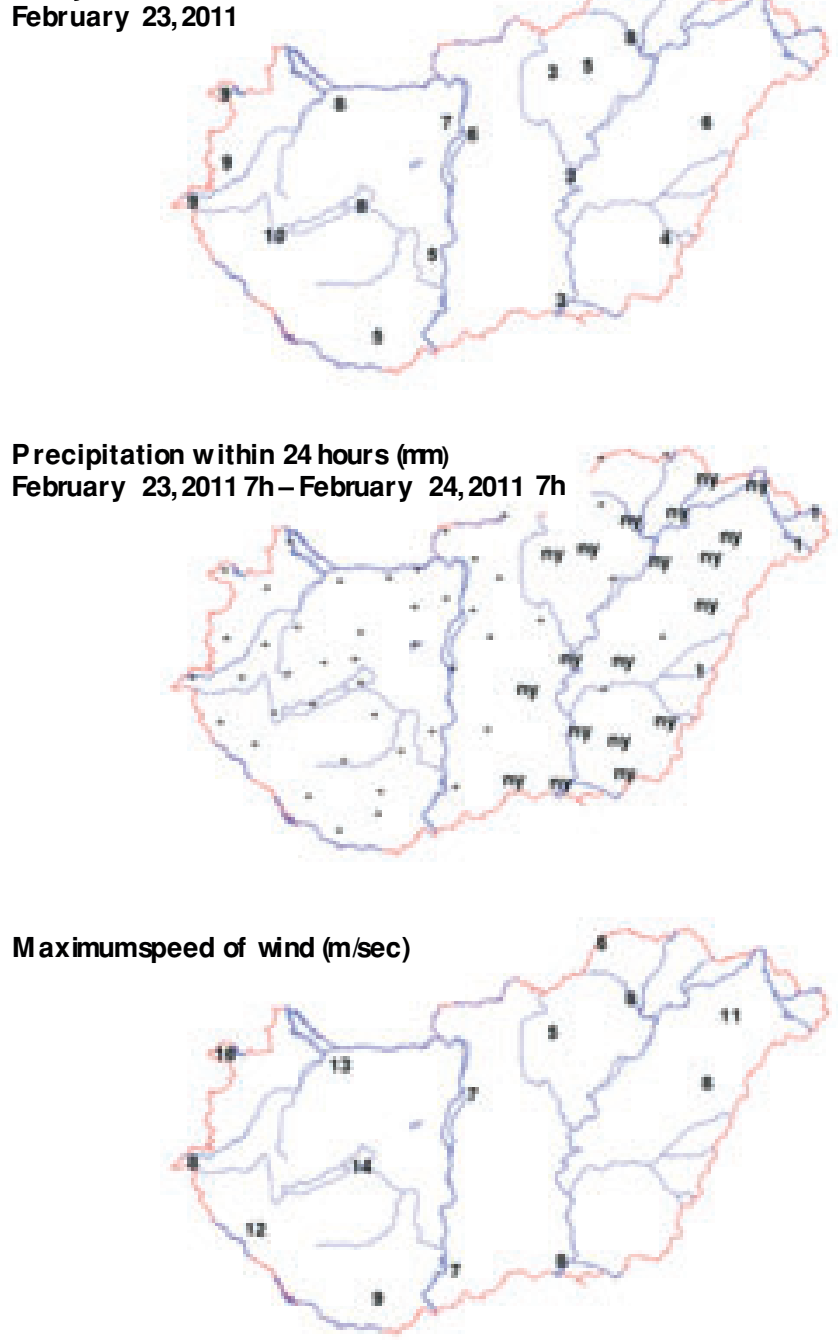

\section{References}

Allen, C.C. (1957): A simplified equation for minimum tempe rature prediction. Mon. Wea. Rev. 85: 119-120.

Bagdonas, J.C., Georg, J.C. \& Gerber, J.F. (1978): Techniques of frost prediction and methods of frost and cold protection. Technical Note No. 157. World Meteorol. Org. WMO No. 487. Geneva, Switzerland, pp. 1-160.

Crawford, T.T. (1965): Frost protection with wind machines and heaters. Meteorological Monographs 6: 81-87.

Gerber, J.F. \& J.D. Martsolf (1979): Sprinkling for frost and cold
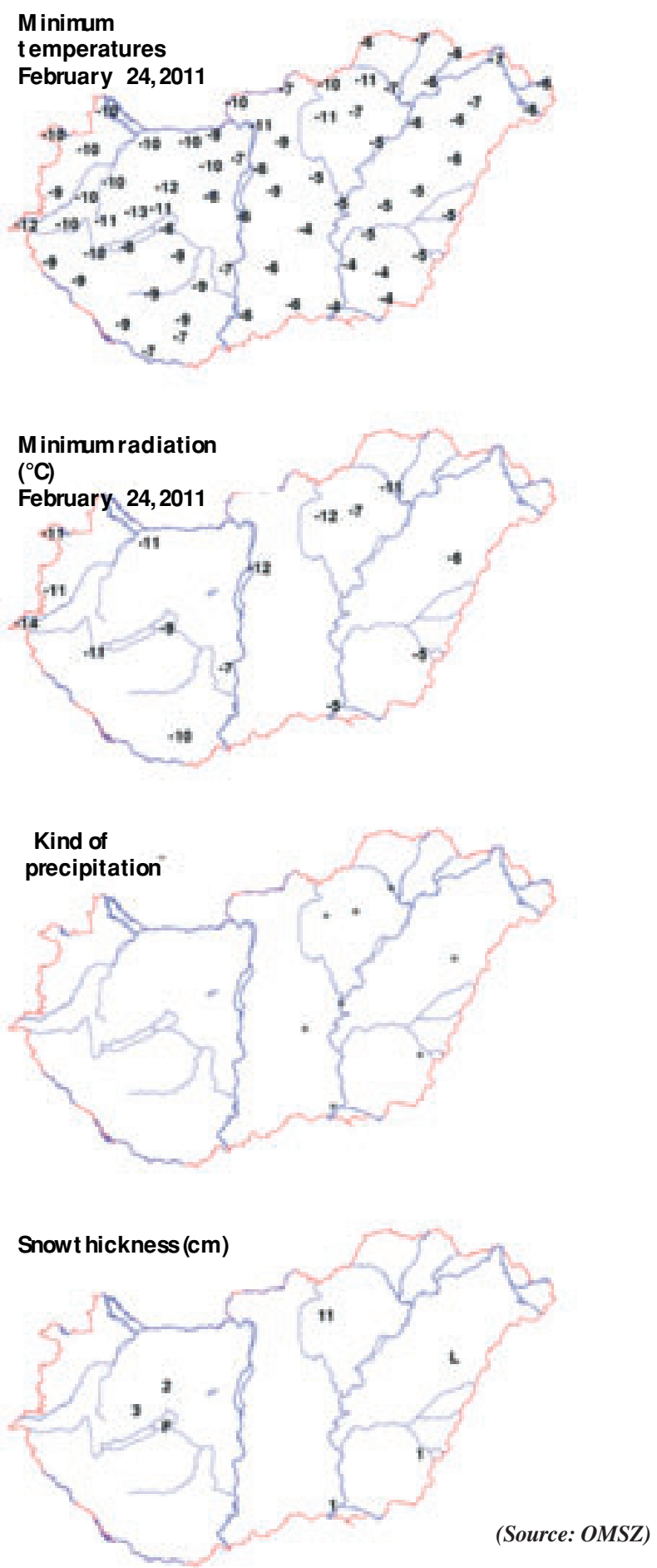

protection. [In Modification of the aerial environment of crops. Eds. B.J. Barfield and J.F. Gerber.] Amer. Soc. Of Civil Eng., St. Joseph, MO., pp. 327-333.

Hagood, L.B. (1967): An empirical method for forecasting radiation temperatures in the Lower Rio Grande Valley of Texas, Southern Regional Technical Memo. No. 33, National Weather Service.

Snyder, R.L. (1986): Frost protection: When to turn the sprinklers on and off. University of California One Sheet Answer 7165.

Young, F.D. (1920): Forecasting minimum temperatures in Oregon and California. Mon. Wea. Rev., 16: 53-60. 